\title{
THE SOCIOLOGICAL STUDY OF THE EMERGENCE OF A CULTURE OF POVERTY (SOCIAL AND ECONOMIC DIMENSIONS) DISCUSSED WITH REFERENCE TO PAKISTAN
}

\author{
Kausar Perveen* \\ Maria Juzer** \\ Munazza Madani ${ }^{* * *}$
}

No one can see the problems of people living in poverty, just like visually impaired persons. The poor citizens are always behind and invisible to others. -Pakistan, 1993

The lower-class people have no job security so they are engaged in multiple jobs, whereas the upper class is skilled with one permanent job. - Poor man,

Pakistan

The poor people should struggle a lot to make their own contacts with people in power to secure a livelihood and future -Pakistan 1993

\begin{abstract}
The present study explores the social and economic dimensions affecting the poverty culture existing in the slum areas of Karachi, Pakistan. The significance of the study highlights the major causes of hindrance in community development poverty and lack of social indicators-which are becoming a culture of the people as their value system along with feelings of powerlessness, meaninglessness, isolation, social exclusion, and selfestrangement in their group relations. This is a qualitative as well as an exploratory research that highlights the emergence of poverty culture in Pakistan for which the researchers have developed an idiographic model to identify the major variables of poverty culture. The researchers in the present study provide the positive and constructive counter-narratives and recommendations against myths about the culture of the poor people. In the present study, researchers have used facts and figures from the United Nations and World Bank Report of Poverty Reduction.
\end{abstract}

Keywords: Culture of poverty, alienation, social indicators, social development, economic development, cultural vitality, community development, vulnerability, De Jour population, social exclusion

\section{Introduction}

Poverty reduction is an overwhelming challenge which is the basic concerned for the development of all social indicators (food, clothing, shelter, life expectancy, education,

\footnotetext{
* Dr Kausar Perveen, Associate Professor, Department of Sociology, University of Karachi

** Maria Juzer, Research Scholar, University of Karachi

**** Dr. Munazza Madani, Assistant Professor, Department of Sociology, University of Karachi
} 
health services, security, clean potable water, environment). The goal attainment of these social indicators is the challenging intervention for community development. Poverty reduction is a reinforcing economic action which can build societal enthusiasm and can strengthen humanity and mankind within the Pakistani society. ${ }^{1}$

Sustainable human development is not only related to the scarcity of resources but environmental development is also the main concern with other social aspects including equal opportunities of education for both males and females, decent health care and equal employment opportunities.

Inflation refers to a doubling in expenditures due to which low-income families suffer to fulfill their basic needs as the prices get high on daily edible items and their income remains the same. Poverty includes the lowest income earners with lack of access to basic social and economic resources. They can improve the quality of living standard through increasing their education. The availability of these social indicators enables the general masses to escape from the culture of poverty. ${ }^{2}$

Due to industrialization, urbanization and urban growth have been increasing rapidly in many developing countries and third world countries. It is changing gender roles, weakening of social bonds among family members and increasing inequality, giving challenges to policy creators and government officials to plan a budget, according to the population so that they can provide sufficient social and economic resources. In the mid$19^{\text {th }}$ century, about half of the world's population lives in cities as they are rich in multiple jobs to fulfill their basic needs. According to the U.N.C.H.S. (United Nations Centre for Human Settlements) projects, it is estimated that during the period 1990 to 2030 the population of urban areas would increase by about 3.3 billion, 90 percent of human population accumulates cities of underdeveloped countries which attracts researchers, sociologists and international organizations towards the culture of poverty. ${ }^{3}$

The UN and World Bank describe poverty as a relative deprivation means the lack of choices and employment opportunities. The lowest income earners living in society are unable to feed and provide clothes for their family so they depend on others for basic goods and services necessary to survive with dignity. It is a situation which creates the feeling of powerlessness, helplessness, frustration, isolation, and depression. The community dwellers do not want to create new policies, loans and schemes for their upliftment and reshaping their lives. ${ }^{4}$

As per HDI (Human Development Index, 2014 Pakistan stands among Low developing countries on $146^{\text {th }}$ ranking with HDI value 0.537 with no notable change during past years 2012-2013. The progress report acknowledges that Pakistan was off track on all nine indicators (food, clothing, shelter, life expectancy, education, health services, security, clean potable water, environment) thus prospects of achieving any of the eight

\footnotetext{
${ }^{1}$ World Health Organization, World Health Statistics, 2015

${ }^{2}$ IMF Country Report Pakistan,Poverty Reduction Strategy Paper, 2016

${ }^{3}$ U.N.C.H.S., Monitoring Human settlements with urban indicators, 2000

${ }^{4}$ World Bank, Poverty Assessment, 2016
} 
MDGs by 2015 were dim. Other nations will attend the forthcoming session with their 15-year MDGs progress reports, but Pakistan does not have a current one. ${ }^{5}$

The SDGs has been settled for a further 15 years in which the goal has been identified end of poverty with different regions of the world.

Pakistan reduction strategy papers (PRSP) contains that the major challenges in achieving developmental goals of Pakistan are to maintain the sustainable economic growth and to eradicate the generational poverty by providing social and economic services including electricity and water supplies, public transportation, telecommunications, roads, and schools. The major objective is to create better job opportunities as well as job security for the general masses living under poverty. Reducing poverty from Pakistani society is still a major challenge. The economic growth along with good governance helps the poor and helpless people to fulfill their basic needs and improve their survival escaping from the culture of poverty. ${ }^{6}$

\section{The essential characteristics of urban poverty culture}

- Low and insufficient family income prevailing under generational poverty and incapacity in the fulfillment of basic needs including food, potable drinking water, clothing, education, safety, and security

- Unequal distribution of wealth, lack of educational facilities, no permanent job security, and housing problem creates the hindrance for individuals, households, and communities.

- The absence of shelter, homelessness, especially poor-quality housing, over populated areas results in lack of health facilities and sanitation.

- The weak groundwork of urban infrastructure piped water used for drinking, defective sanitation, improper drainage of roads and footpaths increases the health burden and work burden among the people living in poverty.

- Due to poverty, general masses have limited or no access to avail services including daycare, schools, vocational training, health care, emergency services, public transport, communication and law enforcement.

- Failure to maintain basic consumption of necessities and lack of shelter and limited health care facilities for their survival is no longer available as much of general masses are prevailing in poverty.

- Protection of law as per requirement of general masses becomes scarce when it comes to availing civil and political rights. General masses are exploited by discrimination via social stratification and racial discrimination. The feeling of

\footnotetext{
${ }^{5}$ WHO, Op.cit.

${ }^{6}$ S. G. Khattak, Sustainable Development, Bridging the Research/ Policy Gaps in Southern Context, 2005
} 
insecurity arises when problems like health hazards, polluted environment and no safety regarding violence and terrorism.

- Organizational structures and systems such as aid agencies, NGOs, public agencies and private utilities are playing vital role in creating awareness through urban poverty programs and eliminating social exclusion and powerlessness and getting a fair response and receiving support from political systems and bureaucratic structures for developing their own initiatives to make fair demands and response. ${ }^{7}$

\section{Situational Analysis in Karachi}

The present study aims to identify the major misconceptions and myths about the culture in the Pakistani society and underlying assumptions in the sustainable development of Karachi. This section articulates against the myths circulating among the citizens of Karachi and alternatively providing positive and constructive counters-narratives and recommendations.

It is the myth that the culture of poor people is fixed, static, inherited, changeless, luxury does not belong to the poor, helpless people ignoring their local identities and behavior. It is the myth that they are powerless in securing and safeguarding their cultural beliefs, practices and traditions at the local level and unable to modify transmitting this cultural identity to future generations. It is also a myth that culture of poverty is a real obstruction and a major hurdle to the social and economic development emphasizing historic heritage, or traditions, or inclusion of disadvantaged people which slows down the economic development of the country. It is assumed that people cannot afford and practice culture at the local level due to insufficient potable safe drinking water, ill health, lack of education, unemployment, lack of decent job, inadequate housing. It is the myth that the culture should be considered secondary and meaningless in the individual' life and should be left to market and household expenditure as the matter of taste (bitter and unpleasant). ${ }^{8}$

Against these myths, the researcher provides the positive and constructive counternarrative which shows that culture belongs to all citizens who are the residents of Karachi having identity among local communities. Identities are always being built and constructed as a key factor in communal projects. The identity provides the universal human rights of individuals which is an integral part of the culture. The human rights framework allows alternative ideas to emerge and flourish towards cultural heritage and diversity. The role of culture for sustainable development is making sure that every woman, man, and children can access and take part in and contribute to cultural life and all this implies. Development has always been understood in economic terms, i.e. Fast growth without equal distribution of resources etc.

\footnotetext{
${ }^{7}$ D. Satterthwaite, The scale and nature of urban poverty in low and middle-income nation,2001

${ }^{8}$ H. P. Muller, Encyclopedia of Social Theory, 2006
} 
Economic development is no more effective without social development because culture is the key component of development, where ideas, behaviors, and practices can be widely discussed in a pluralistic and democratic country. ${ }^{9}$

Similarly, legislative frameworks, cultural policies, and support programs in Karachi are quite essential to maintain urban sustainability and in handling environmental issues as well as in creating a greener city. But due to limited legislative frameworks, targeted policies, bureaucratic silos and reluctance (unwillingness) encounters difficulties to fulfill the socioeconomic of the poorer sector of Karachi, especially integrating culture among urban planning and economic policies. ${ }^{10}$

Lack of education and myths creates misunderstandings by the citizens of Karachi regarding the word 'culture' and its different meanings. Cultural diversity can be a source of social tension may produce a silo effect that is often hostile to people-centered cultural policies vary from individual to collective. ${ }^{11}$

Cultural vitality is an absolute necessity to urban life because it spreads through all spheres of living and lies at the foundation of freedoms, the public exchange of ideas, and societal well-being. It is important for local governments to provide social environments that actively encourage public among democratic debates and decision making where citizens of Karachi can exercise their rights, their abilities to survive in the present and decide best for their future. Thus, it is concluded that sustainable development in the urban society cannot take place without culture, as it is a core element in the local communities and local urban policies. ${ }^{12}$

\section{Opportunities and challenges for the government in Karachi}

Local government occupies as an important bridge between citizens and communities as well as national governments and international frameworks. Local governments in culture play several roles which include creating and activating spaces for dialogue and action, setting priorities and planning, designing, implementing and monitoring policies and programs, developing infrastructure, and enabling environments and structure relating to a variety of transformative functions within the territories of Karachi. ${ }^{13}$

Karachi as the metropolitan city consists of dynamic cultures with a wide range of expressions and values with intangible cultural heritage, contemporary arts; collective and individual activities characterize a unique way of living practicing Islam. In the urban areas, diversity of cultures, heritages, and knowledge provides people as hubs of social and human development for communities to fight with the poverty culture. ${ }^{14}$

\footnotetext{
${ }^{9}$ K. Singh, Urban Sociology, 1996, pp129-130

${ }^{10}$ S. Anwar, Social Problems of Pakistan, 2003

${ }^{11}$ A. H. Taga, Sociology and social problems, 2007

${ }^{12}$ K. Singh, Op.cit. pp 131-134

${ }^{13}$ R. F. Francine, City Politics, and Planning 1970

${ }^{14}$ A. H. Taga, Sociology and social problems, 2007
} 


\section{Why do people prefer to live in poverty?}

The culture of poverty and social exclusion are deeply interrelated to each other. Social exclusion has always an explosive negative impact on social and economic dimensions of increasing poverty, including 'discrimination', 'isolation', and 'deviant, from institutions as well as leading to a poorer sense of well-being. ${ }^{15}$

When a child born into a low-income family, where the poor father cannot educate him and live in the generational poverty for several decades. The child also adopts the same environment as his culture and remains in continuity from generations to generations. ${ }^{16}$

Within the Pakistani society, it has been seen that norms and values are neglected by the people because of lack of education and no goal setting. They prefer to live in poverty as their culture in their mindset and adopted the feeling of helplessness and powerlessness as their lifestyle and cultural identity.

After fifty-five years since Pakistan came into being, policies and projects formulated and implemented by bureaucrats and planners should reinforce them by images, stories, proverbs, and movies to change their mindset and create awareness that they can change their patterns of attitudes and behavior as well as their lifestyle by themselves through dignity, pride, and self-respect. ${ }^{17}$

\section{Theoretical Background of the Study}

Constantly living in the poverty of certain groups makes us understand the persistence of poverty culture. Modern settlements are badly affected by the culture of poverty since the years is adopted by the people as their value system; they have accepted the capacity living in poverty as their social condition. ${ }^{18}$

The concept of Lewis is simultaneously explained by Karl Marx in the theory of alienation; those are living in poverty culture. They assumed themselves as socially excluded from the prevailing system. Robert Blauner (1964) separated Karl Marx culture of alienation as the culture of poverty into four dimensions of powerlessness, meaninglessness, isolation, and self-estrangement in the group relations. ${ }^{19}$

Similarly, Anthropologists, Oscar Lewis (1959) promulgate the term "culture of poverty" that depicts specific patterns of attitudes and behaviors that change their standard of living as well as their feeling of "powerlessness" due to detachment within group relations. ${ }^{20}$

Another theory by Ruby Payne refers to the living in poverty by choice since generations. They made their own traditional values that are not matched to the middle class of the

\footnotetext{
15 D. Narayan et. al., Voices of the Poor,2002

${ }^{16}$ R. Lister, Poverty, 2004

${ }^{17}$ G. Breese, Urbanization in Newly Developing Countries, 1996

${ }^{18}$ D. Gordon, and P. Spicker, The International Glossary on Poverty, 1999

${ }^{19}$ D. P. Moynihan, On Understanding Poverty,1969, pp 187-195

${ }^{20}$ Ibid., pp 195-200
} 
society. People are characterized by least concern about the future planning and they believe in day -to -day life.

Different research highlights that dependency on others is the major cause of people living in poverty for generations. Unemployment, insecurity, and instability stem from powerlessness and helplessness. The feeling of helplessness and powerlessness arises as they are always dependent on others and are unable to protect themselves from exploitation and abuse. ${ }^{21}$

The budget 2015-2016 did not mention the climatic change as a major challenge to economic growth. There is an extreme poverty where forests have disappeared. The budget allocations for poverty alleviation, health and education are nothing but a pittance. ${ }^{22}$

As per Rostow's stages of growth, Pakistan is still lying on the pre-conditions for take-off into self-sustaining growth, but the national development is not even at the take-off stage so it is far to reach maturity. To overcome from low human development, we must achieve 9 indicators to come up with medium human development. ${ }^{23}$

Ruby Payne's term 'culture of poverty' is a modern social problem existing among the people of slum areas in Karachi suggesting that poor people have choices in their surroundings about whether to remain in poverty or not. For that these deprived people have to change their 'mindset 'and 'misconceptions'. ${ }^{24}$

Ruby Payne's Book "Framework for Understanding Poverty" seems as though poverty is a choice that one makes.

Simultaneously, the first stage of the pyramid of Maslow's theory hierarchy of needs approaches the physiological and biological needs, which are the primary needs of human beings as well as compulsory to be fulfilled for their survival in the society. Due to poverty as their choice, their lower level needs remain to be unsatisfied to reach the level of transcendence. ${ }^{25}$

People adopted the culture of poverty always felt a decline in economic opportunities due to their dependence on others, inadequate food and assets, and lack of job security resulting in the greater participation of the poor people in illegal gang activities and drug abuse. Crime, corruption, and violence are the major effects of lack of social cohesion and disintegration. The poor person feels helpless and frustrated against the rapid social change due to industrialization and modernization. ${ }^{26}$

\footnotetext{
${ }^{21}$ D. Narayan et al., Op.cit.

${ }^{22}$ U.N.C.H.S., Op.cit.

${ }^{23}$ M. P.Todero, Economic Development, 1997, pp.71,75-76

${ }^{24}$ D. P. Moynihan, On Understanding Poverty, 1969, pp 200-220

${ }^{25}$ R.Nauert, Updated Maslow's Pyramid of Needs, 2015

${ }^{26}$ D. Narayan, et. al., Op.cit.
} 


\section{Research questions}

- Why there is no change in the life of poor people as they are provided facilities by the government, international organizations, and NGOs?

- How do the poverty culture and each of its variables support the economic, social and cultural goals of the society?

- To what extent does the government of Pakistan affirm the twin challenges of reviving growth and reducing poverty?

- How do well the social development professionals seek to develop new methods, skills, and approaches to overcome the challenges of poverty culture?

\section{Methodology}

This is an exploratory research to explore the emergence of poverty culture in Pakistan for which the researcher has developed an idiographic model that can help us in explanation of the very many, unique consideration that lies behind a given action. ${ }^{27}$ This model grips with the reasons for human behavior which probed the multiplicity of reasons that would account for a specific behavior. It is important to realize that the idiographic model is employed frequently in many different contexts, to understand the actions of the people around us. ${ }^{28}$ In the present study, the researcher has used facts and figures from the United Nations and World Bank Report on Poverty reduction report.

${ }^{27}$ S. Sarantakos, Social Research, 1993

${ }^{28}$ E. Babbies, The practice of Social Research, 2012 


\section{Poverty Culture}

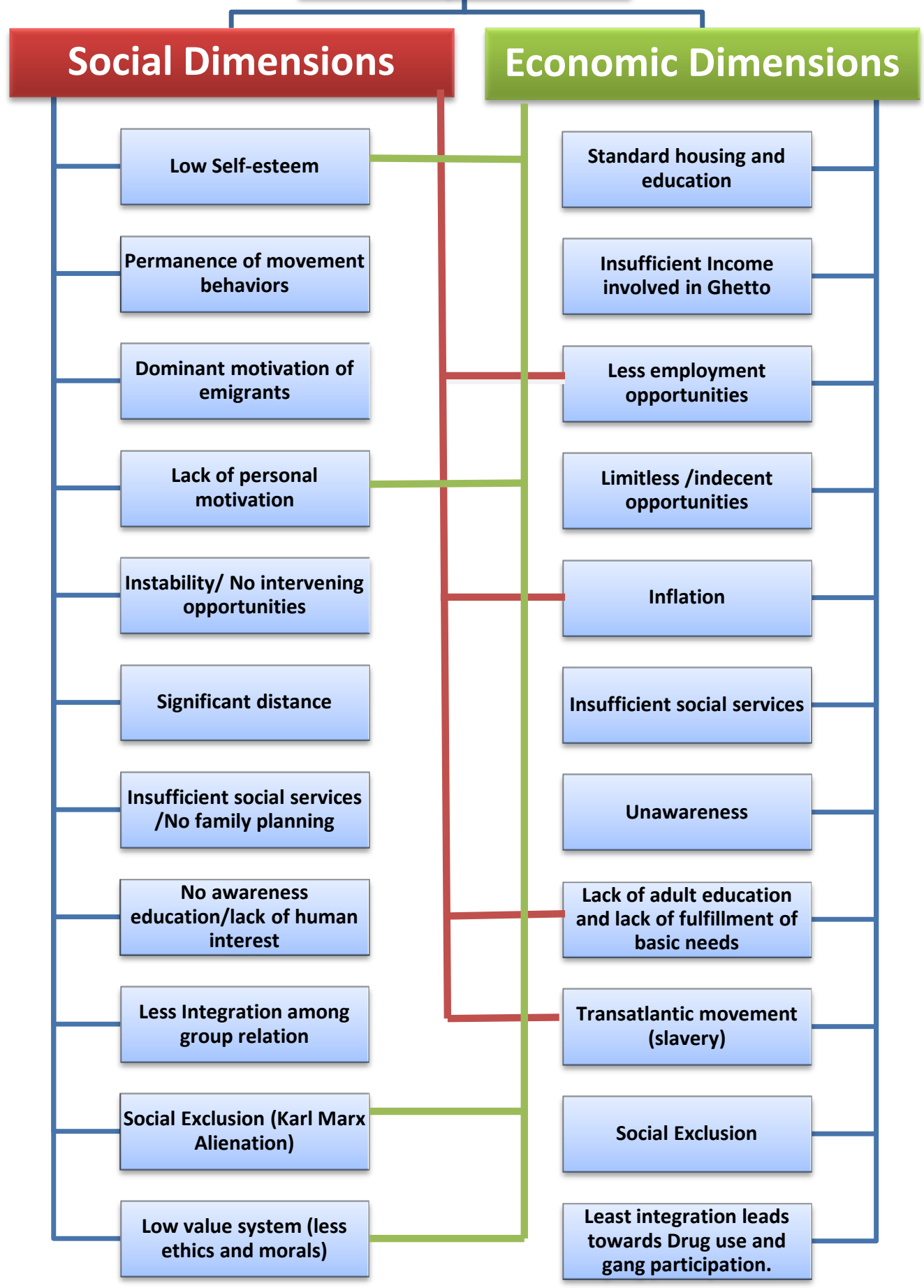




\section{Analysis of the Data}

This research paper explores the two dimensions of poverty culture, i.e. social dimensions and economic dimensions. As per year 2016, the current estimated population of Pakistan is 194.63 million, among which population aged $0-14$ years is $35.2 \%$ and aged $15-64$ years is $60.3 \%$ of the total population, as per the year 2014 with the natural increase at the rate of $1.89 \%$, increasing dependency ratio $58 \%$, which is more than half of population affecting income and expenditures and size of an average household and its composition by sex and quintiles due insufficient resources. As per survey 2012-13, $26.5 \%$ of the total population of Pakistan is living in severe poverty. ${ }^{29}$ Feeling of helplessness and powerlessness arises as they are always dependent on others and are less likely to protect themselves from exploitation and abuse.

As per the year 2013-14, the average number of total member per household is $6.41 \%$ (Male $=3.22 \%$, Female $=3.20 \%$, and Children $=2.79 \%$ ). The average monthly income per household in all areas of Pakistan is Rs.30,999 (Rural=Rs.26,452 and Urban=Rs.38,923) but the families living in slum areas are less likely to earn on the average income prevailing under a low self-respect. The unemployment rate for persons (10 years and over from both sexes is $5.9 \%$ (Male $=5.0 \%$ and Female $=9.0 \%$ ), whereas the unemployment ratio in urban areas of Pakistan $8.0 \%$ (Male $=6.2 \%$ and Female $=20.4 \%$ ) which shows the dependency of unemployed females and the ratio of childbearing women is $54.3 \%$ in urban areas of Pakistan resulting in dependency which is the major cause of people living in poverty for generations. ${ }^{30}$ As per survey $2012-13,14.9 \%$ of the total population is living near poverty while $6.1 \%$ of the population is living below income poverty line. ${ }^{31}$

Low self-respect may be education, as per the year 2014-15 in urban areas of Pakistan $0.34 \%$ has no formal education, $17.32 \%$ are illiterate, $34.83 \%$ are pre-matric, $15.77 \%$ are matric but below inter, $8.66 \%$ are intermediate but below degree and $23.08 \%$ are with Post-Graduate degree whereas in rural areas of Pakistan $0.21 \%$ has no formal education, $27.4 \%$ are illiterate, $31.84 \%$ are pre-matric, $13.23 \%$ are matric but below inter, $11.57 \%$ are intermediate but below degree and $15.74 \%$ are with Post-Graduate degree, thus the overall literacy ratio in Pakistan is $60 \%$ and other $40 \%$ generally have no access towards education and have no awareness and desire to be educated. ${ }^{32}$

This rapid increase of population leads to sub-housing without sanitation and health services. As per the year 2013-14 the proper sanitation system all over Pakistan is just $3 \%$ covered drains, $36 \%$ are open drains and $24 \%$ is underground drains and $37 \%$ of the areas have no system of sanitation in the country which are spreading various harmful diseases and $32.3 \%$ of population have no to health facilities to get cure due to which

\footnotetext{
${ }^{29}$ United Nations Human Development Index, Human Development for Everyone,2016)

${ }^{30}$ Lewis, O. Culture of Poverty. In Moynihan, Daniel P. On Understanding Poverty: Perspectives from the Social Sciences. (New York: Basic Books. 1969), pp. 187-220.

${ }^{31}$ Ibid.

${ }^{32}$ Lewis, O. Op.cit.
} 
infant mortality, maternal mortality, health, disease, and poliovirus HIV/AIDS and other infections are spreading widely all around the country. ${ }^{33}$

Slum areas are characterized by substandard housing structures by type of toilet as per the year 2014-15, 73\% have flush connected to public sewerage, $13 \%$ have non-flush toilets and remaining $13 \%$ have no toilets in their households.31.6\% of the total population have insufficient living standards providing shelter to the homeless and people living in poverty. Overpopulation and rapid urbanization are creating hurdles for government officials, urban planners and city dwellers that are facing quiet difficulty in meeting the growing demands for well-planned housing, urban services, and infrastructure. ${ }^{34}$

Access to Education is the right of every citizen of the nation. $60.7 \%$ is the total literacy rate in Pakistan which falls by $2 \%$ during the economic survey 2016-17, among them $70 \%$ males and $48 \%$ females. $55 \%$ of total population has lack of skills and illiteracy which creates high unemployment. The decrease in literacy rate has been watched in Sindh, Balochistan and Punjab while it remained declining in Khyber-Pakhtunkhwa (K-P). ${ }^{35}$ Lack of adult education and lack of fulfillment of basic needs are the root causes of growing violence and participation in illegal gang activities. ${ }^{36}$

HDI ranking of Pakistan is constant at 147 out of 169 countries in comparison to other neighboring as per 2015-16 ranking reports. Inequality in life expectancy at birth is $32.8 \%$, inequality in education is $44.4 \%$ and inequality in income is $11.6 \%$ showing an increase in poverty and failure to reduce vulnerability in Pakistan. ${ }^{37}$ Unemployment is an important source of vulnerability; even few days without work can represent a serious financial blow involving them in the informal economy. ${ }^{38}$

In Pakistan, only $27 \%$ of households have access to safe potable drinking water through motor pump and tube well outside the house, $26 \%$ of the population have hand pump inside and outside of their houses, $3 \%$ have access to drinking water through dug well open and closed both inside and outside the house, $27 \%$ have access to drinking water through tap water inside and outside the house, and $11 \%$ others includes public standpipe (supplied by tanker), water seller, canal, river, spring, stream, pond and other. ${ }^{39} 60 \%$ of the total population has electricity in their houses, buildings, shops, and workplace. Only $8 \%$ of waste is treated and purified and only $12 \%$ of solid waste is recycled and the rest of the solid waste remains on the roads and in the gutter pipelines. Manholes are widespread in many areas of Karachi, making unsatisfactory hygiene conditions and the unhealthy physical environment. Plantation and greenery eliminate from the society and the government officials have utilized those areas in the construction of bridges and flyovers due to overcrowding and increasing population.

\footnotetext{
${ }^{33}$ WHO Op.cit.

${ }^{34}$ A. H.Taga,Sociology and social problems, 2007

${ }^{35}$ R. Haq,Ministry of Finance: Economic Survey,2017

${ }^{36}$ I. Khan, Social Indicators of Pakistan, 2016

${ }^{37}$ United Nations Human Development Index, Human Development for Everyone, 2016

${ }^{38}$ Ibid.

${ }^{39}$ Ibid.
} 
Insufficient basic urban services and poor infrastructure are a major challenge faced in the progress of human development. Similarly, results showing permanence of movement were associated with insufficient income involved in ghetto behaviors as they have no choice due to poor education and insufficient income to fulfill their basic needs and at the same time there feeling of helplessness, dependency, marginality, and powerlessness forced them to participate in gang activities and illegal method of getting money such as earning through selling drugs, snatching ornaments, cash, mobile from people increasing street crimes. In year 2011the figure of all reported crime was 673,750 and in the year 2015 all reported crimes were 633,600, however, there is decrease in all reported crimes in the current years. ${ }^{40}$

Similarly, results showing that there is associated with the dominant motivation of emigrants and limitless/ indecent opportunities as the researcher explores that there is no motivation to enhance their lifestyle due to sufficient aids and programs without having sustainable financial activities.

In the same way, the researcher explores that lack of personal motivation is associated with fewer employment opportunities due to the feeling of helplessness and dependency which leads them towards failure, self-motivated and remain unemployed and more likely to dependent on aids and programs. As per survey the year 2012-13, the intensity of deprivation among total population of Pakistan is 52.0\% and only $31 \%$ of Pakistanis feel that they have freedom to pursue what they want with their lives. ${ }^{41}$

Similarly, results show that inflation is associated with instability/ no intervening opportunities. It occurs in the society when there is an economic instability, lack of new employment opportunities and job insecurity among the people. Inflation Rate in Pakistan averaged 9.69 percent from 2012, which leads the country towards socioeconomic instability. The socioeconomic instability gives birth to injustice and inequality attributing the failure in the functioning of social policy, housing, education, and urban health care services. ${ }^{42}$ Inflation Rate in Pakistan is expected to be 4.20 percent by the end of this quarter, per Trading Economics global macro models and analysts' expectations. Looking forward, we estimate Inflation Rate in Pakistan to stand at 5.10 in 12 months' time. In the long-term, the Pakistan Inflation Rate is projected to trend around 3.30 percent in 2020, as per our econometric models.

Similarly, results showing that significant distance is associated with insufficient social services, as the social workers and community health worker are unwilling to go in distant areas due to terrorism. The government and the police officials are unable to provide them security and protection. The horrific killings of volunteers providing polio vaccinations in slum areas have raised fear and threat, so the persons are less likely to visit those distant places to give protection to these children against incurable disease.

Comparable results showing that insufficient social services/No family planning leads to unawareness. It is obvious that lack of knowledge that polio drops are compulsory for the

${ }^{40}$ United Nations Human Development Index, Human Development for Everyone, 2016

${ }^{41}$ J. Beall,\& S. Fox,Cities and Development, 2007

${ }^{42}$ UN HDI, Op.cit. 
prevention of polio. Because of the significant distance and lack of security social workers and NGO workers avoid visiting those slum areas and the people living in those localities remained less likely aware and illiterate about the knowledge of health, education, family planning, safety and socialization of their coming generations.

Similarly, results show that lack of fulfillment of basic needs is associated with no awareness education/lack of human interest. As Per World Bank's poverty Head Count Analysis for 2014, income per adult in Pakistan is taken as $\$ 1.25$ per day than $43.1 \%$ are extremely poor due to lack of education, health facilities, and poor living standards as they have no human interest and self-motivation in social learning and to become skillful to earn money to live a better living and satisfy their basic desires. This feeling of powerlessness reduces their self-motivation and human interest making them more likely to be unemployed and more likely to practice ghetto behavior.

A result shows that social exclusion is associated with less integration among group relations. Social exclusion is a multi-dimensional process circulates unequal distribution of economic opportunities, lack of political participation, and lack of cultural involvement among individuals, households, groups, and communities. Lack of integration, hostility and hard feelings among family members of the household gives birth to the feeling of alienation and socially excluded from the society.

A result showing that social exclusion is associated with transatlantic movement (slavery). When the social norms became weak and isolated and there is a lack of interaction and integration among family members, powerlessness, meaninglessness, isolation, and self-estrangement in group relationship are more likely to create the feeling of exclusion and transatlantic movement slavery.

Similarly, results showing that low-value system (fewer ethics and morals) are associated with the least integration leads towards Drug use and gang participation. There are higher chances of involving in gang participation (ghetto behaviors) and more likely to be an addict due to the isolation and lack of integration among group relations.

\section{Recommendations}

The researcher in the present study recommends that the people belonging from lowincome families can improve their lives if the man and woman work hard to perform their duties with responsibility according to their rights and stop depending on others to satisfy their wants and basic needs.

Child labor is very common within low-income families to fulfill and satisfy their basic desires. Children work in auto mechanic shops, garages, garbage collectors, etc., destroying their physical and mental health. Imparting informal education will develop interest and motivate these children and bring them towards school education and will get more skilled with professional degrees to have permanent jobs gaining self-respect in the society. 
Adult education is very much important. If the elders are educated, they will educate their children, which will not only increase the literacy rate of the country but will also protect youth from delinquency, illegal gang activities (ghetto behaviors) and drug abuse.

The sociologists, social workers and NGO's should organize awareness programs and seminars to disseminate knowledge about family planning so that their family size shrinks. The government officials and urban planners can plan better social services and upliftment policies to empower the individuals living in generational poverty. Through equal distribution of government, resources will protect them from exploitation.

The government officials and bureaucratic organization should work to expand job opportunities for poor people so that they can satisfy their wants by themselves. Lack of spare time will reduce their participation in illegal gang activities, creating violence and terrorism in the society. Leisure time can be made useful by giving them vocational training so that they get skillful and make it as the earning source to run the livelihood and escape themselves from the culture of poverty.

\section{Bibliography}

Muller H. P. et. al.,Encyclopedia of Social Theory, (2006), published by Routledge Taylor and Francis Group, printed in New Jersey, America.

Babbies, E.,The practice of Social Research,(2012), $13^{\text {th }}$ edition, Wads Worth Publishing Company.

Beall, J. \&Fox, S.,Cities and Development, (2007), Routledge: London.

Breese, G.,Urbanization in Newly Developing Countries, (1996), published by PrenticeHall, Inc., Englewood Cliffs, N.J, Printed in the United States of America Ed. Modernization of Traditional Societies Series.

Gordon D. and Spicker P.,The International Glossary on Poverty, (1999), Zed Books, London.

Haq, R.,Ministry of Finance: Economic Survey, (2017), published by Education Sector, printed by The Express Tribune Newspaper, Pakistan. Retrieved from: https://tribune.com.pk/story/1419396/economic-survey-literacy-rate-pakistan-slips-2/

IMF Country Report Pakistan, Poverty Reduction Strategy Paper: International Monetary Fund, (2016), Washington D.C. URL: http://www.imf.org

Khan I., Social Indicators of Pakistan, (2016), published by Government of Pakistan: Statistics Division, printed by Pakistan Bureau of Statistics, Retrieved from www.pbs.gov.pk

Khattak S. G., Sustainable Development, Bridging the Research/ Policy Gaps in Southern Context, Vol: 2: Social Policy, (2005), Published by Sustainable Development Policy Institute, (SDPI), and Printed in Pakistan by Ibn-e-Hassan offset Printers, Karachi. 
Lister R., Poverty, (2004), Cambridge: Polity.

Moynihan, D. P., On Understanding Poverty: Perspectives from the Social Sciences, (1969), New York: Basic Books. Pp. 187-220.

Narayan, D. et al.,VOICES OF THE POOR: Can Anyone Hear Us, (2002), $3^{\text {rd }}$ edition, printed and published by Oxford University Press for World Bank, New York.

Nauert R.,Updated Maslow's Pyramid of Needs, (2015), retrieved from https://psychcentral.com/news/2010/08/23/updated-Maslow's-pyramid-ofneeds/17144.html

Francine, R. F., City Politics, and Planning, (1970), $1^{\text {st }}$ edition, Volume 10, published under the Urban Study Centre of Rutgers University, printed by Atherton Press, Inc.

Sarantakos S., Social Research, (1993), 7th edition, Australia: MacMillan.

Satterthwaite, D., The scale and nature of urban poverty in low and middle-income nations, (2001), Urban Poverty Conference Paper, Lusaka,5-9 February

Anwar, S., Social Problems of Pakistan, (2003), $1^{\text {st }}$ edition, published Emporium Printed by Nasir Baqir Printers, Rattigan Road, Lahore.

Singh, K.,Urban Sociology, (1996), revised and enlarged edition published by Prakashan Kendra, Lucknow, India, and Pages 129-134.

Taga A. H., Sociology and social problems, (2007), published by Abdul Hameed Taga and Sons Publishers, printed a Nadeem Younus Printers, Lahore.

Todaro P. M., Economic development, (1997), $6^{\text {th }}$ edition, published by Addison-Wesley publishing company, Inc., printed in the United States of America, pages 71, 75, 76.

U.N.C.H.S (United Nations Center for human settlements), (2000),Monitoring Human settlements with urban indicators, Nairobi. http://unchs.org/guo

United Nations Human Development Index, Human Development for Everyone, (2016) retrieved from: http://hdr.undp.org/sites/all/themes/hdr_theme/country-notes/PAK.pdf

World Health Organization, World Health Statistics, (2015), published by WHO Press, Switzerland and printed in Luxembourg.

http://apps.who.int/iris/bitstream/10665/170250/1/9789240694439_eng.pdf World Bank, World Development Indicators, (2013), Washington, D.C., World Bank.

World Bank, Poverty Assessment: A Process Review,(2016), published and printed by Operations Evaluation Department Document 15881. Washington, D.C.: World Bank 